\title{
WOMEN ISSUES IN PANDEMIC TIMES: SOCIO ECONOMC EFECTS OF COVID - 19 ON GENDER PARITY
}

DOI: 10.36108/ljerhrm/2202.03.0110

FAPOHUNDA, Tinuke Moradeke PhD

Department of Industrial Relations and Human Resource Management

Lagos State University Ojo. Nigeria

tkfap@yahoo.com

and

DOPAMU, Ifeoluwa Oluwaseyi

Department of Industrial Relations and Human Resource Management

Lagos State University Ojo. Nigeria

dopamuifeoluwa@gmail.com

\begin{abstract}
The effects of pandemics are always gender biasedtherefore, the recovery efforts cannot be gender neutral. Although families are subjected toconsummatetests, women are enduring the weight of the economic and social penalties of COVID-19.Gender inequality precipitates gender inequality, and the practice is simply aggravated in periods of crisis or principal blows like the COVID-19 pandemic. To appreciate the effects of the pandemic and to plan policy reactions to the present pandemic, it is significant to take note of prevailing gender disparities and their tendencies to mediate gender influences and roles. Also, to articulate policies that consider established circumstances to deliver a tailored methodology. Governments must pro-actively reach out to women for assistance with tackling the pandemic because of women's larger engrossment with care of children and the elderly, plus their home-based activities and the actuality that the home is characteristically their purview. Women's empowerment during this time is consequently more treasured because of their prospective inputs to the response endeavours. The need arises to communicate responses that will consider gender inequalities. The disparities in gender consequences of the pandemic are intensified in specific settings and among particularly susceptible groups. Women and girls who experience various levels of inequality tend to be particularly susceptible. The gender-segregated influence of the COVID-19 pandemic must likewise be contemplated for poverty measurement and forecasts. This paper examines the direct and indirect gender consequences of the COVID-19 and offers suggestions towards strategic recovery efforts so that women and girls are not left behind.
\end{abstract}

Keywords:Covid-19, Effects. Gender, Issues, Pandemic,Parity,Socio Economic, Women

\section{Introduction}

Across countries globally, gender gaps in results across endowments, agency and economic chances continue. The influences of the COVID-19 epidemic are augmented by those established gender disparities. Principally, the adverse influences can be anticipated to worsen and excavate. Gender gaps are affected in diverse ways contingent on the circumstances and particular features of diverse groups of women. Furthermore, both in the initial stage of prevention and control, and in the follow up, those similar dissimilarities could necessitate varied roles in the attempts to combat the predicament. For instance, women are placed at a privileged situation in communication and prevention endeavours owing to their roles as caregivers both in the households and communities. 
The fact that women and girls have the propensity to be affected in specific manners, and in some areas, experience additional negative effects compared to men is indicated by the effects of infectious disease epidemics similar to COVID-19. More operative reactions and accomplishments can consequently be permitted by keeping the gender consequences of COVID-19 in prospect.

The effects of pandemics are on no occasion gender-neutral, and COVID-19 is no exclusion. Many families' life and activities have stopped for women in developing countries like Nigeria arising from the COVID-19 lockdown measures and restrictions. Workloads have blown up for numerous women in economies of all sizes, accompanied by unsteady earnings, free and meagre care facilities and domestic work. Though families are experiencing unparalleled challenges, women are enduring the burden of the economic and social consequences of COVID-19.Poor and relegated women experience even greater dangers of COVID-19 infection and casualties, forfeiture of income, and augmented violence. World Health Organisation (2020) affirms that universally, 70 per cent of health workers and first responders are women, nevertheless, they are not at parity with their male colleagues. WHO (2020) adds that at 28 per cent, the gender pay gap in the health sector is above the total gender pay gap which is 16 per cent?

\section{The Coronavirus /Covid-19 Disease}

Sili (2020)asserts that the Coronavirus disease (COVID-19) is an infectious disease caused by a recently discovered coronavirus. The virus spreads mostly through droplets of saliva or nose discharges when an infected person coughs or sneezes. Most persons infected with the COVID-19 virus experience minor to modest respiratory illness and recover without requiring special treatment. However, WHO (2020) observes that older people and those with fundamental medical problems such as cardiovascular diseases, diabetes, chronic respiratory diseases, and cancer have a greater tendency to cultivate serious illnesses.

COVID-19 is a disease which originated form Wuhan in China towards the end of year 2019. The first index case of the dreaded Corona virus (COVID-19) disease was recorded in Nigeria on the $27^{\text {th }}$ February, 2020. The dreaded Coronavirus came into Nigeria through an infected Italian national who after being infected, came in contact with a Nigerian citizen, who was consequently infected with the dreaded virus. The virus then began spreading to other citizens in Lagos and other parts of the country. On the $17^{\text {th }}$ of March 2020, it was recorded in Lagos specifically with three (3) confirmed cases and later in Abuja and Ogun states respectively with twenty-two (22) confirmed cases. The Nigeria Centre for Disease Control (NCDC 2020) reports that by the 30th of March, 2020, it had aggravated to 131 confirmed cases from Lagos, Abuja, Bauchi and Enugu. Afterwards, the disease spread to the 36 states of the federation (NCDC, 2020). Following the further raze of the virus, it became obvious that in Nigeria and globally; the pandemic was (particularly for women, girls in their adolescent stages, women with disabilities and other vulnerable groups in society) more of a socioeconomic than medical situation. The United Nations (2020) states that, the Covid-19 pandemic expanded the pre-existing inequalities thus uncovering the susceptibilities in the framework of social, political and economic structures which consecutively intensified the imports of the pandemic where women were typically affected as they are an enormous part of the informal sector. 
Fapohunda (2012a) affirms that notwithstanding their enormous and substantial inputs, arising from cultural influences, women have been dominated, plagued and downgraded in virtually all activities in the Nigerian society. Women are considered as the pillar of development in any society desirous of remarkable growth. Though women constitute facilitators of transformation they have been at pronounced handicap practically in every area of concern in the country owing to the fact that culturally, they are considered as the weaker sex, subservient who play the part of second fiddle in the society. Additionally, Falola (2020) observes that the ravaging Covid-19 has affected women because they were at the receiving end; regarding unpaid care, sexual and gender-based violence, income decrease, upsurge in domestic stress, elevated level of rape incidents, and quarantine sometimes with abusive partners in the course of the lockdown.

This paper examines the gender dimensions of the Covid-19 effect in Nigeria. Itscrutinizes the vast consequences of the outbreak of the Covid-19 virus on the social well-being, and economy of women. The study contributes to intellectual discourse on the subject matter to generate a broadspectrum consciousness on the consequences of the COVID-19 pandemic on women and proposes actions to assuage and moderate the pains of the women. The study is quite fundamental because it offers contribution in disentangling obligatory prospects needed by women interest groups to participate in objective advocacy with policy makers at various levels on the concentration and route of reactions to concerns troubling women.This paper offers a synopsis of related literatures and previous studies in the area of covid-19 pandemic and the level of effects it has on women. It is sub divided into: Covid-19 and Women in Nigeria, Implication of Covid-19 on Women in Nigeria and Strategic Recovery Efforts to Protect Women.

\section{Covid-19 and Women in Nigeria}

The COVID-19 pandemic is rolling back on the female gender with austere agonies that intersect economic, business, religious, family, domestic and society discomforts among others. In the first place, the most affected industries have more women. Women are over represented in industries like the informal sector, food services, retail and entertainment all of which have been most impacted by the COVID-19 pandemic.World Bank (2020a) reports that 40 per cent of all working women -510 million women worldwide- work in hard-hit sectors, in contrast to 36.6 per cent of working men. Informal employment, where workers previously experienced low pay, poor working conditions and deficiency insocial protection (pension, healthcare, unemployment insurance) before the pandemic is common within some of these sectors.ILO (2020) observes that universally, 58 per cent of working women are engaged in informal employment, and estimates submit that informal workers worldwide lost an average of 60 per cent of their earnings during the earliest months of the pandemic. Women's paid labour and women-run businesses have been hit hardest. More women have lost their jobs. The pandemic and measures to check its spread are motivating a disparate escalation in women's unemployment in contrast to men and similarly dwindling their total working time.

Sex segregation in sectors and occupations initiate disparities in economic effects in the short, medium and long term. The effect on men in relation to women is contingent on whether their jobs are continuous during the containment period. Counter-cyclical industries like government and 
education and those making an allowance for telecommuting are at a greater danger of fading away. Some of the economic activities that have been badly disturbed include leisure, travel, hospitality, textile and apparel manufacturing and retail sales (aside from super stores and pharmacies). Fapohunda (2013) reports that in Nigeria, women dominate the informal sector where most of this is situated. Again, Rutkowski (2020) asserts that roughly 50 percent of the working women in Bangladesh are employed in textile or ready-made garment manufacturing. Already, in Nigeria, many informal sector workers, who are predominantly women, have been laid off devoid of more pay because of COVID-19. Rutkowski \& Bousquet (2020)notes that in the US, 60 percent of the 700,000 jobs that were jettisoned in the first wave of the pandemic, were held by women. By and large, as obtains in Nigeria too, above half of the workers in these jobs are women. Fapohunda (2012b) indicates that in Nigeria, as in many other countries globally, amongst the self-employed and small business owners which have likewise been principally impacted by the crunch, women are similarly over-represented.

With everybody staying at home, domestic workers were laid off. Thus, globally, for domestic workers, 80 per cent of whom are women, the situation has been grim. ILO (2020) affirms that an astounding 72 per cent of domestic workers have lost their jobs. Even preceding the pandemic, similar to numerous other informal economy occupations, paid domestic work was without rudimentary worker protections such as paid leave, notice period or severance pay.Again, as earlier noted, women constitute enormous proportions of the health workforce globally, though they possibly possess lesser decision-making capability within the health sector and have reduced access to protective equipment in situations of crisis in comparison to male health workers. The World Health Organization WHO(2020) affirms that globally, between 85 percent (Africa) and 86 percent (Americas) of nurses are female, although doctors are excessively male (excluding some countries in Europe). Besides, the hierarchical connection between nurses and doctors could undercut the standpoint of (female) nurses. Carter, Dietrich \& Minor (2017) asserts that after the SARS epidemic, nurses that took part in focus group discussions conducted in Canada contended that doctors' defiance of infection control protocols threatened their health and safety. Nkangu, Olatunde \& Yaya. (2017) also notes that nurses, traditional birth attendants, and cleaners /laundry workers in health facilities (who are predominantly women) were not offered the equivalent amounts of protective gear given to (male) doctors and other high-ranking hospital officials during the 2014 Ebola outbreak in Nigeria. In the same vein, female health care workers experience stigmatization in some settings. Women have a crucial role in the response to the pandemic and erstwhile practices demonstrate that they are a fundamental part of the solution.

Women organizations and female leaders have the ability to offer significant perceptions, and pertinent dissimilarities in messaging and disaster management. While women constitute the main stream of frontline healthcare workers, which put them at an advantageous situation to recognize drifts on the ground, they remain principally under-represented in national and global health leadership posts.

Similarly, in informal sectors of the health workforce, like home health care, aids or community health workers, women are susceptible. Both women and men exist in particular segments and professions (like store cashiers, hospital cleaners, teachers and pharmacists for women, security 
forces, transport and logistics among men). All of them continue to be very active and are principally unprotected in the pandemic. UNDP (2020) reports for instance that in Germany, 2.38 million women are employed in the retail industry in contrast to 1.23 million men, and nearly 2 million women work in pharmacies as opposed to about 0.5 million men.

Another issue is that women constitute majority of the primary caregivers to the ill even at home and this additionally exposes them to the infection. Gender dissimilarities exist with respect to caregiving roles and preventive behaviours that are required to be reflected on in community and public health messaging in particular circumstances. Women, who conventionally have the duty of care for children and the elderly, frequently continue to be responsible for caring for the ill during pandemic outbreaks. UNDP (2020) affirms that throughout the 2013-16 Ebola epidemic in West Africa, social expectations that women and girls have a duty to care for sick family members and follow cultural practices of care for bodies after death put women and girls at a greater danger, but refusal to care for the sick was considered as a stark moral inadequacy. The crisis in West Africa indicated that women and girls were more exposed to infection owing to their responsibilities as caregivers.

Moreover, Minor (2017)notes that as indicated from the Ebola crisis the public health messages commending women not to offer care controverted social norms about their roles as caregivers. Women were put in a problematic situation because good mothers and wives were anticipated to care for the sick and the deceased. Additionally, women could experience definite restrictions in accessing health services during pandemics. Nkangu, Olatunde and Yaya (2017) suggest that in numerous high-income countries, even after adjusting for reproductive care visits, compared to men, women have more prospects of seeking health care. Likewise, in majority of developing countries like Nigeria, out of pocket expenditure on health is greater for women compared to men. Nevertheless, in specific situations, social norms could inhibit women from accessing health services by themselves or when the benefactors are men. For instance, Minor (2017) designates that during the 2013-16 Ebola outbreak in West Africa, in a particular region, if a woman left the family home, even for child delivery in a hospital, it was regarded as an indication of failure to fulfil their domestic obligations. Men typically fail to perform domestic tasks in the absence of their wives and this consequently forces some women to stay at home instead of seeking medical support. Equally, Evans (2020) contends that in India boys have more prospects of being taken to a qualified health professional for treatment.

Furthermore, in periods of public health crisis, crucial services like sexual and reproductive health are disturbed with harmful results for women. Fawole et al (2016)reports that in the Ebola outbreak in the Democratic Republic of Congo it was hard to provide particular sexual and reproductive health services comprising care for survivors of family violence. Universally, maternal mortality is increased because women are frequently incapable of accessing reproductive care services. Korkoyah and Wreh (2015) report that circumstantial evidence submits that women and small children were disturbed because of inaccessibility to mundane maternal and child health services, plus pregnant women being deprived of access to clinics and having to employ dicier homebirths. Onyango, Resnick, Davis \& Shah. (2019) observes that pertaining to SARS in Asia, comparable outcomes were witnessed which was linked to an extraordinary occurrence of maternal and neonatal 
difficulties. World Bank (2020b) observes that in South Africa 65 percent of the casualties of H1N1 were women of reproductive age, of whom almost half were pregnant. There are now estimates that designate that COVID-19 left millions of women and girls out on crucial family planning services in 2020.

While boys will likewise be touched, the educational effects of a public health crisis of these dimensions are particularly enormous for girls in certain countries like Nigeria. Arising from the closure of schools and confinement measures, home-schooling or distance learning has become obligatory for children to sustain the programme and materials. Furthermore, obtainable gender disparities in the employment of digital resources and IT consequently disturbs access to education for girls vis-à-vis boys during the pandemic. UNDP (2021) asserts that the capability of women and children to sustain home-schooling materials is limited across low and middle-income countries, because women are still $8 \%$ less prospective compared to men to own a mobile phone, and $20 \%$ less possible to employ the internet on a mobile. Simultaneously, girls in some middle- and low-income countries like Nigeria are supposed to undertake household and family care responsibilities, which leave them with less time for home learning.

Besides, the pandemic increases existing inequalities in home and unpaid care. Both for women and men, as quarantine measures kept people at home, with closed schools and day-care facilities, the burden of unpaid care and domestic work has blown up.Even prior to COVID-19, worldwide, while men spent on the average just about 1.7 hours daily on unpaid work, women spent 4.1 hours doing same; implying that women did three times more unpaid care work compared to men.Both men and women testify to an upsurge in unpaid work since the pandemic started, nevertheless women are persistently bearing the bulk of the work. The closure of schools and daycare centres, added to the reduced accessibility of external help has resulted in months of extra work for women. Generally, arising from the pandemic and the reaction to the rapid spread of COVID-19, women have had numerous care responsibilities and have experienced a substantial encumbrance on their time. Women are excessively affected by the school closures because they are typically responsible for all informal care in the household and could subsequently perceive their work and economic prospects as additionally inhibited. As witnessed in earlier and comparable crises across and within countries, added to child care duties, women are expectedly the ones assuming foremost care duties for the elderly (who are predominantly susceptible to COVID-19) and the sick. This weight is even greater in lower-income settings and particularly among families living in shanty towns, IDP camps or equally deprived conditions where illness due to COVID-19 and other diseases can be anticipated to rise. For employed mothers, this inevitably implies balancing full-time employment with childcare and schooling duties.

As frequently occurred subsequent to the Ebola crisis in Western Africa, the closure of schools as part of the control endeavours, results in numerous girls that previously faced pressure to drop-out to forever remain out of education. Attributable to this, gender gaps in access to education rises. For example, Wodon, Montenegro, Nguyen \&Onagoruwa (2018) notes that influence evaluation research in Sierra Leone found that girls in the control group faced a 16-percentage point tenacious reduction in school enrolment after the emergency. Onyango, Resnick, Davis \& Shah. (2019) report that the 
closure of schools added to the fact that majority of the orphaned girls became the primary caregivers at the household risks the formation of a 'lost generation' dispossessed of formal education. Simultaneously, to subsidize household income generating activities and as a down side of the calamity, boys could be pressured out of schooling.

Adult women in developing countries including Nigeria are characteristically less well educated compared to men and less well plugged into information systems. Nkangu,OlatundeandYaya (2017)affirm that an assessment of Medecins Sans Frontiers' Ebola response in Guinea determined that consciousness and education programmes had restricted effect since they lacked a knowledge of local norms. Earlier experiences in epidemic outbreaks indicate that distinct efforts must be made to reach women with information about COVID-19 and its prevention since their role of trained women in the prevention and containment efforts in their communities and families is fundamental. Lives could be saved by considering gender dynamics. This could be by way of directed messages to women on the significance of employing protective measures in and outside the home. Another effect of the pandemic involves the prospect of the poverty gender gap. The World Bank (2020b) observes that worldwide for over 22 years, extreme poverty has been disturbing. This is now compounded by COVID-19, and the attendant enormous job losses, dwindling economies and forfeiture of livelihoods, mostly for women. Deteriorated social protection schemes have left several of the poorest in society defenceless, without defences to withstand the storm. The revival of great poverty on account of the pandemic has further exposed women's hazardous economic safety. Fapohunda (2012c) contends that women usually earn less and occupy less protected occupations than men. Women are principally susceptible to downsizings and loss of incomes arising from the prevailing plunging economic activities.

The susceptibility of women to poverty especially in periods of crisis is worsened by their overrepresentation among the inactive population, and in susceptible types of employment. The low levels of female labour force participation in Nigeria could be worsened by COVID-19. Fapohunda (2012b) reports that in Nigeria, irrespective of their income level, women are inclined to be more present than men in all types of vulnerable occupations, like the informal sector, non-standardized work, unpaid and domestic work. An implication of this is that they are essentially excluded from the coverage of social protection instruments, comprising for example support directed at workers during crises. Wodon et al. (2017) contends that issues motivating early marriage comprise socio-economic features like poverty or poor educational and employment prospects for girls, and cultural features, besides social norms. In certain cultures, it is frequently an "either/or" alternative between getting married or continuing in school. There is a tendency for boys to get preferential treatment for household outlays in schooling, at least at the secondary level where poverty makes it tough for a household to send all children to school. Additionally, there is the propensity to keepgirls home from school to aid in care or housework because parents in old-fashioned societies could put a lesser worth on girls than boys.

Even though girls from poorer socio-economic backgrounds have higher prospects of early marriage, marrying early could initiate a greater probability of being poor later in life. The leading effects of child marriage are connected to upsurge in fertility and population explosion, poorer educational and 
health upshots and reduced lifetime earnings. Women in lower-income settings are especially susceptible to poverty and the harmful effects of food scarcity due to a public health crisis. Additionally, the greater mortality of men on account of COVID-19 escalates the possibility of losing a (prospective) income earner in affected households, resulting in amplified economic susceptibility for the surviving women and children.

UNFPA (2020) affirms that with the COVID-19 epidemic, the income generation capability and facility to sustain their families by women migrant workers in Asia, particularly those involved in domestic work, were badly affected. Women in Nigerian households, are being forced to undertake negative survival contrivances, like lessening food consumption by girls and women or early marriage. This is attributable to the decrease in income and livelihoods on account of the slow-down in economic activity added to the lack of sufficient safety nets.

Gender disparity consequences for economic opportunities and income or consumption can be attributable to several factors. One has to do with the sectors, professions and natures of work in addition to access to social protection. Sectors and professions in which women and men are represented to different levels are impacted contrarily by the confinement procedures, border closures and the go-slow in economic activities provoked by the COVID-19 crisis. Women and men are impacted differently on account of gaps in their engagement in susceptible types of employment, like informal or part time work, self-employment and domestic work; primarily, as a result of the most instantaneous effects on their work circumstances; and additionally, since they are deficient of rudimentary formal social protection. Again, there are widespread social norms and bargaining power in the household in the management of contradictory work and care mandates. There is a swell in the need for care within households attributable to schools' closure, the amplified defencelessness of the elderly and the snowballing number of ill people who are unable to access health services or COVID-recovery patients. How well-adjusted the distribution of this rising care need is controlled by the prevailing social and gender norms and the bargaining power of men regarding women in the household. Regardless, these clashing requests has a tendency to result in decreases in working time or resolutions to select one occupation in the household. In this perspective patriarchal social norms regulating access to assets, for example associated to land use, inheritance or finance, must in addition be deliberated.

Furthermore, there are other (non-labour) market surprises. Travel limitations, border closures or interruptions to public transport consequence drops in international (and domestic) remittances. Accurate documentation of the kinds of households that rely on remittances and their composition is imperative. For domestic workers or small-scale traders who are predominantly women, upsurges in prices and limitations to mobility has an undesirable effect on their incomes.

These results will outlive the crisis. Economic uncertainty goes beyond mere jobs, and loss of earnings now. It has a bourgeoning influence on the lives of women and girls for coming years. Effects on education and occupation have elongated significance that, if not tackled, can motivate reversals in the toughly earned achievements in gender equality. UNESCO (2020) estimations demonstrate that a further 11 million girls could drop out of school by the end of the COVID emergency and evidence from preceding crises proposes that several will not return. The result will be most austere for the very susceptible women like migrant workers, refugees, downgraded racial 
and ethnic groups, single-parent households, youths and the world's poorest. Those who have newly become fugitive to life-threatening poverty have prospects of falling back into it.

Further non-labour market interferences could excessively affect women and girls. The World Bank (2020a) denotes those indications from the 2008 financial crisis demonstrate that instability in prices of staple and other foods could portend particularly negative effects for women and girls in many of the most susceptible households. Women and girls in Nigeria are usually more susceptible to the damaging imports of food insecurity and are more regularly compelled to embrace extreme survival devices. In many parts of Nigeria, where women are primarily liable for subsistence crops, more of them could be employed to smooth consumption or vended on local markets, making poorer returns. In the wake of the Covid-19 outbreak in Nigeria, the loss of income owing to deteriorations in food and crop production, sharp escalations in costs of food, waning food security and closed borders has affected female smallholder farmers and cross-border traders brutally. Many self-employed women engaged in food businesses and the sale of perishable goods like fruits and vegetables, (which went to waste due to the lockdown and customers' frights of contacting the virus) suffered huge financial loses. Men on the other hand are mostly engaged in businesses involving non-perishable goods and were capable of remaining in business or instantly reopening once the conditions improved.

Several families across higher-income communities are challenged by the necessity to elect to prioritize the utmost-paid job in the household (most frequently consistent with men), in the lack of any substitute support apparatus. More generally, women have a higher propensity to stay out of the labour market as the catastrophes hit especially in settings where the male breadwinner prejudice continues and precedence in periods of shortage of jobs is apt to be given to men. Simultaneously, in some circumstances, contrasting forces could eventually stimulate gender equality in the labour market since businesses are speedily embracing flexible work arrangements that could continue, though some fathers are beginning to take charge of childcare, which could grind down the existing social norms.

Also, the eruption of an infectious disease might likewise intensify gender dissimilarities regarding access to productive assets and property in particular settings. Women who become widowed are in danger of disinheritance and forfeiture of property in some Nigerian communities. Widows commonly constitute an extremely susceptible population group as women's property rights are frequently qualified by marriage.

Meanwhile, women face increased dangers of gender-based violence in the perspective of public health emergencies. The World Bank (2020a) established this to be true in all previous epidemics, with the most frequent types being intimate partner violence, sexual exploitation and abuse. The report affirms that accounts from numerous countries distressed by COVID-19 designate that genderbased violence has been on the rise, probably linked with the blend of augmented tension, worry and quarantine circumstances in the home. In Nigeria, Falola (2020) reports a sharp upsurge in domestic violence across the country from the time when the pandemic started. In the same vein, United Nations (2020) observes that there were augmented dangers of violence and harassment touching frontline female health workers added to extraordinary levels of terrorization and belligerence to female health professionals, particularly nurses. Escalations in violence in pandemic situations could 
be attributable to economic stress, confinements and social separation, the possible collapse of societal infrastructures, family separation, decreased admission to services, or the powerlessness to escape abusive partners.

Because access to critical security and support services are more limited, there is an amplified perception of immunity by perpetrators. The rising pressure on the health system along with the social distancing procedures caused by the spread of COVID-19 has resulted in disturbances to care and support services for women survivors of gender-based violence. Service provision (like medical, justice) for victims of gender-based violence has broken down due to the COVID-19 outbreak. The combination of all these with the mandatory confinement in the household as part of the measures to limit the spread, resulted in a higher perception of latitude by perpetrators.

Furthermore, thanks to inferior education levels, marginalization from male networks, power arrangements and societal constraints on women's mobility, there is the tendency for them to be deprived in access to dire information. Moreover, since women have less prospects than men to wield power in decision making, their requisites are principally not met. This implies that the exclusive obligation to self-manage their risk outline is on women, signifying those men do not have any obligation for generating an unequal gender dynamic to the pandemic.

In Nigeria as in several countries, women have been hit hardest by Covid-19 lockdowns. United Nations (2020) notes that they had 50\% more prospects compared to men to lose a job in the pandemic's initial stages. Again, women are inclined to be profoundly employed in susceptible sectors like retail, restaurants, hospitality and informal jobs (like selling goods on the streets and sewing at home) that are deficient in protections like paid sick leave or unemployment insurance. With the disappearance of those jobs, women had no social safety net for contingency. World Bank (2020a) indicates that Nigeria's per capita GDP could be increased by over $25 \%$ with a reduction in gender inequality. In places with the severest pandemic lockdowns, like Lagos, women-owned businesses have 10 percent more probability to close compared to those owned by men since majority of women-owned businesses are inclined to be smaller sole proprietorships or informal microenterprises having less than five employees. Improvements in gender equality in the workplace is another fatality of the coronavirus, as women find their positions in the work force more threatened. Around the world, working women face vicious tough choices about staying at home with their children, if they have not before now been made redundant. As if working mothers did not have enough to worry about, development concerning gender equality is the newest in a long list of fatalities of the coronavirus pandemic.

\section{Strategic Recovery Efforts to Protect Women}

Frazer (2020) contends that notwithstanding the obvious gender repercussions of crises, rejoinder and retrieval attempts seem to overlook the requirements of women and girls until it is belated. The need thus arises for improvement. UNFPA (2020) and ILO (2020) suggest that data must be gathered and publicized segregated by sex, age and other features like class, race, location, disability and gender. Severe shortages in critical data make it tremendously hard to envisage the pandemic's complete effect across countries and communities. Wahome (2020) adds that the COVID-19 policy rejoinders must pay attention to the primacy of the most susceptible women and girls. Consequently, 
to alleviate the harmful economic influences of COVID-19 on women, efforts must be made both by governments and private entities in several areas. There must be direct income backing for women. To this end, economic sustenance packages, comprising direct cash-transfers, extended unemployment subsidies, tax reliefs, and extended family and child subsidies for susceptible women and their families need to be presented. This could constitute salvation for those fighting to meet the expenses of everyday needs. Such measures offer palpable assistance that women require immediately.

Additionally, sustenance for businesses retained and controlled by women are required. Such businesses should get particular grants and stimulus funding, besides endowed and government sponsored loans. There must be ease in tax burdens. Also, economic respite must focus on sectors and industries boasting women as huge percentage of workers. Backing must be given to women workersby instigating gender-responsive social security schemes to assist in income security for them. Extended admission to inexpensive and quality childcare services for example, will facilitate more women remaining in the labour force. It is imperative to close the gender pay gap, and it can be instigated by passing laws and policies that assure equal pay for work of equal value and discontinuing devaluation of the work women do. Moreover, support must be given through social protection and benefits to informal workers. For informal workers left jobless, cash transfers or unemployment benefits can assist in easing the financial weight, in addition to conceding or exempting taxes and social security payments for employees in the informal sector. Efforts have to be made to reconcile paid and unpaid work by offering all principal caregivers paid leave and reduced or flexible working agreements. Childcare services must be provided for essential workers. While some procedures have been put in place to tackle the economic outcome, relatively limited efforts have been focused on assisting families contending with paid and unpaid work, together with care requirements. Additional efforts are also desirable to involve citizens and workers in public campaigns that encourage evenhanded sharing of care and domestic work between men and women.

Arising from the foregoing, this paper recommends that since the enormous achievements on girls' education access and enrolment have been affected by the pandemic, procedures for re-entry to education must be addressed. Again, subsistence rates in secondary education which has now developed after the lockdown comprising the possible growth in the portion of boys out of school need to be addressed. The reversals on women's economic activity (employment, entrepreneurship, agricultural production, others) that has been witnessed is a fundamental area of interest.The Covid19 pandemic recovery efforts must consider the requirements of women and girls. Policymakers have not constantly reflected on the fact that economic shocks affect women and men differently and that this should influence government responses. Women must be the focus of strategies as leaders tackle the huge challenge of reconstructing post- Covid-19 pandemic economies. Economically relegated women are frequently unseen by governments and have reduced tendencies to possess formal identification or appear in a social registry. Therefore, in cooperation with the private sector, policy makers in Nigeria can hasten the digitization of government identification schemes, payment platforms and other serious services. Nigeria continues to struggle to ascertain and provide aid to informal workers, denoting that many women remain discounted while several countries have cultivated social-protection measures in response to the Covid-19 pandemic. Innovative digital 
schemes can support in ascertaining indigent women so they can obtain cash speedily and securely. Sex-disaggregated data and a digital infrastructure added to ownership of bank accounts by the women will aid access to pandemic-relief payments.

Governments must also certify that economic chances are equitably distributed. Obstacles to women's total inclusion in the economy either as entrepreneurs or employees should be eliminated. A pandemic amplifies all prevailing disparities. Working from home in a white-collar employment is easier; workers with salaries and benefits tend to be better sheltered; self-isolation is not as demanding in an expansive house as in a poky apartment. A very striking effect of the coronavirus is to send several families back to the 1950s. Closing gender gaps in entrepreneurship would assist in poverty reduction, generating employment, and motivating development and innovation. Government must consequently aim lines of credit and other systems of finance at women-owned businesses, improve the formation of e-commerce platforms to allow female entrepreneurs to access markets, and aid business incubators in overcoming biases regarding investing in women-owned businesses.

\section{Conclusion}

Across the world, women's independence is a noiseless casualty of the pandemic. This paper concludes that impact assessments of the diverse initiatives being established and executed must reflect on the gender undercurrents emphasised in this paper. COVID-19 has multi-dimensional influences on women, who constitute the mainstream population in many Africa countries. Women are disparately disturbed by the influence of the pandemic, and discounting their apprehensions and requirements in the COVID-19 responses, could intimidate the amalgamation of the improvements achieved in the expansion of gender equality, women's empowerment and women's rights not only in Nigeria but in Africa. It is consequently imperative that responses in the direction of COVID-19, consider gender parity and women's empowerment, with the intention of not leaving women and girls behind.

\section{References}

Carter, S. L., Dietrich, O. and Minor, O. (2017). Mainstreaming Gender in WASH: Lessons Learned from Oxfam's Experience of Ebola. Gender and Development, 25(2),205-20.

Evans, D. (2020): How Will COVID-19 Affect Women and Girls in Low- and Middle-Income Countries? https://www.cgdev.org/blog/how-will-covid-19-affect-women-andgirls-low-and-middle-income-countries

Falola, T. O, (2020). The role of Nigerian women. Www.britannica.com Accessed March19, 2021

Fapohunda, T. M. (2012a).Women and the Informal Sector in Nigeria: Implications for Development. British Journal of Arts and Social Sciences, 4(1), 35- 45

Fapohunda, T.M. (2012b).Women and Poverty Alleviation in Lagos, Nigeria. British Journal of Humanities and Social Sciences, 3(2), 87- 99.

Fapohunda, T.M. (2012c). Towards Improved Access to Full Employment and Decent Work For Women in Nigeria.International Journal of Humanities and Social Science, 2(8), Special Edition); 104- 112. 
Fapohunda, T.M. (2013).The Gender Pay Gap in Nigeria: Causes and Remedies. Mediterranean Journal of Social Sciences, 4(2), 211-220.

Fawole, O., Bamiselu, O., Adewuyi, P. and Nguku, P. (2016). Gender Dimensions to the Ebola Outbreak in Nigeria. Annals of African Medicine, 15(1),7-13.

Fraser, E. (2020). Impact of COVID-19 Pandemic on Violence against Women and Girls, VAWGHelpdesk Research Report No. 284.

ILO (2020). Social Protection Responses to the COVID-19 Pandemic in Developing Countries: Strengthening Resilience by Building Universal Social Protection https://www.ilo.org/wcmsp5/groups/public/---ed_protect/---

soc_sec/documents/publication/wcms_744612.pdf

Korkoyah, D. and Wreh, F. (2015). Ebola Impact Revealed: An Assessment of the Differing Impact of the Outbreak on Women and Men in Liberia. UN Women, Oxfam, Ministry of Gender and Development, Liberia Institute of Statistics and Geo-information Services, Liberia Wash Consortium, Action Faim, Concern Worldwide, PSI, Tearfund, WaterAid. https://www-cdn.oxfam.org/s3fs-public/file_attachments/rr-ebola-impact-women-menliberia-010715-en.pdf

Minor, O. M. (2017). Ebola and Accusation: Gender and Stigma in Sierra Leone's Ebola Response. Anthropology in Action, 24(2), 25-35.

Nigeria Centre for Disease Control (NCDC) (April 9, 2020). COVID-19 case update. https://twitter.com/NCDCgov/ (accessed 18th March, 2021).

Nkangu, M., O. Olatunde, and Yaya, S. (2017). The Perspective of Gender on the Ebola Virus Using a Risk Management and Population Health Framework: A Scoping Review. Infectious Diseases of Poverty 6:135. NYT: Coronavirus and Poverty: A Mother Skips Meals So Her Children Can Eat. Ac cess at: https://www.nytimes.com/2020/03/20/us/coronaviruspoverty-school-lunch.html

Onyango, M.,Resnick, K., Davis, A and Shah, R. (2019). Gender-Based Violence Among Adolescent Girls and Young Women: A Neglected Consequence of the West African Ebola Outbreak. In. D. Schwartz, J. Anoko and S. Abramowitz (Eds.) Pregnant in the Time of Ebola: Women and Their Children in the 2013-2015 West African Epidemic. Global Maternal and Child Health book series, Springer: Cham, Switzerland: 121-32.

Rutkowski, M. (2020). How social protection can help countries cope with COVID-19. World Bank blogs. https://blogs.worldbank.org/voices/how-social-protection-can-help-countries-copecovid-19

Rutkowski, M. and Bousquet, F. (2019). Social protection: Protecting the poor and vulnerable during criseshttps://blogs.worldbank.org/dev4peace/social-protection-protecting-poor-andvulnerable-during-crises

Sili, L. (2020). COVID-19 and The Impact on Women. International Growth Centre https://www.theigc.org/blog/covid-19-and-the-impact-on-women/

UNDP (United Nations Development Group) (2020). Socio-Economic Impact of Cocid-19 in West African Countries: A Call for National and Regional Containment, Recovery and Prevention https:// www.undp.org/ content/dam/ rba/docs/Reports/ebola-west-africa.pdf. Retrieved from https://www.undp.org on March 21, 2021. 
United Nations (2020). Policy Brief: The Impact of COVID-19 on W o m e $n$, A p r i 19 , a v a i 1 a b 1 e a $\mathrm{t}$ https://reliefweb.int/sites/reliefweb.int/files/resources/policy-briefthe-impact-ofcovid-19-on-women-en.pdf Retrieved from https://www.undp.org on March 23, 2021.

UNESCO (2020). COVID-19: School Closures Around the World will Hit Girls Hardest. Plan

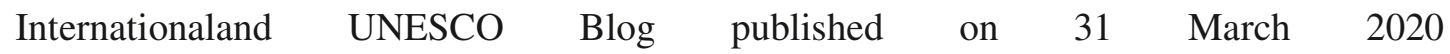
https://planinternational.org/blog/2020/03/covid-19-school-closures-hit-girls-hardest

UNDP (2021).Impact of the COVID-19 Pandemic on Family Planning and Ending Gender based Violence, Female Genital Mutilation and Child Marriage https://www.unfpa. org/sites/default/ files/resource-pdf/COVID _19_impact_ brief_ for_ UNDP_24_April_2020_1.pdf

UNFPA (2020). Coronavirus (COVID-19) Guidance Document. UNFPA Asia Pacific Region.

UNFPA (2021). COVID-19: A gender lens.

Wahome, C. (2020). How Covid-19 Pandemic Has Impacted Women Working in Flower farms.Hivos Article. Published 28 May 2020 https://www.hivos.org/assets/2020/05/HivosRapidAssessment-2020.pdf

WHO Coronavirus Disease (COVID-19); dashboard www.who.int Accessed March, 26, 2021.

WHO (2020). Addressing the Challenge of Women's Health in Africa - Report of the Commissionon

Women's Health in the African Region https://www.afro.who.int/sites/default/files/201706/report-of-the-commission-on-

Wodon, Q, Male, CH., Nayihouba, A., Onagoruwa, A., Savadogo, A., Yedan, A., Edmeades, J., Kes, A., John, N., Murithi, L., Steinhaus, M. and Petroni, S. (2017). Economic Impacts of Child Marriage: Global Synthesis Report. Washington, DC: The World Bank and International Center for Research on Women.

Wodon, Q., Montenegro, C. Nguyen, H. and Onagoruwa, A. (2018). Missed Opportunities: The high cost of not educating girls. Washington, DC: The World Bank.

World Bank (2018). Poverty and Shared Prosperity Report 2018. Piecing Together the Poverty Puzzle. Washington DC, World Bank.

World Bank (2020a). Supporting Women throughout the Coronavirus (COVID-19) Emergency Response and Economic Recovery. Gender Innovation Lab.

World Bank (2020b). Gender-related inequalities emerging from Covid-19: Preliminary thoughts on impactsand recommendations: Focus on Transport sector. 